\title{
Correction to: Valve-sparing aortic root surgery. CON: remodeling
}

\section{Takashi Kunihara ${ }^{1}$}

Published online: 8 January 2018

(c) The Japanese Association for Thoracic Surgery 2018

\section{Correction to: Gen Thorac Cardiovasc Surg https://doi.org/10.1007/s11748-017-0833-6}

In the original publication of this article, Tables 3 and 4 were published incorrectly. The correct Tables 3 and 4 are given in the following page.

The original article can be found online at https://doi.org/10.1007/ s11748-017-0833-6.

Takashi Kunihara

kunihara@cvi.or.jp

1 The Cardiovascular Institute, 3-2-19 Nishiazabu, Minato-Ku, Tokyo 106-0031, Japan 


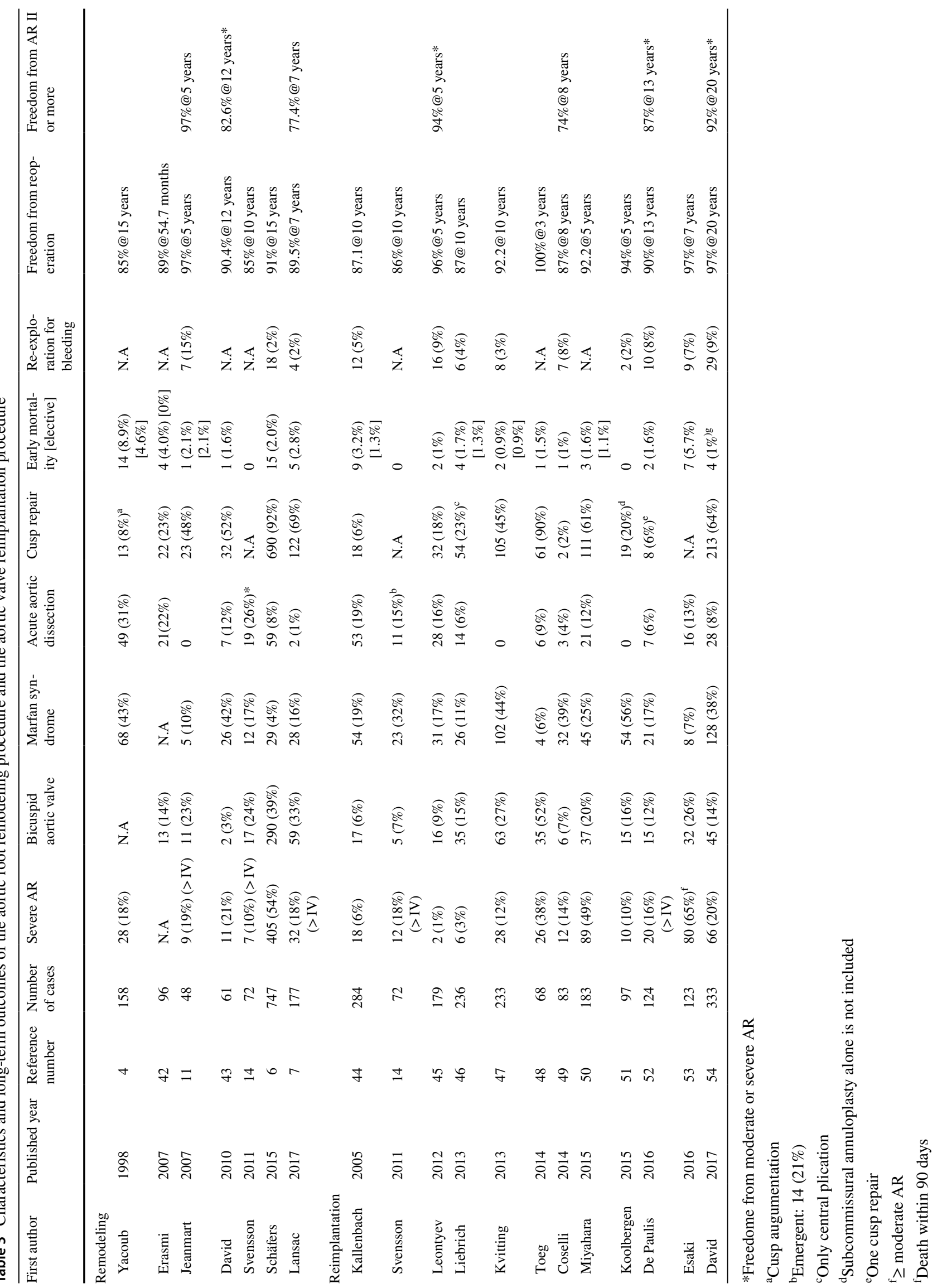


Table 4 Long-term outcomes of the aortic root remodeling procedure and the aortic valve reimplantation procedure in cases with the bicuspid aortic valve

\begin{tabular}{|c|c|c|c|c|c|c|}
\hline First author & Published year & $\begin{array}{l}\text { Refer- } \\
\text { ence } \\
\text { number }\end{array}$ & $\begin{array}{l}\text { Number } \\
\text { of cases }\end{array}$ & Mean Follow-up & Freedom from reoperation & Freedom from AR II or more \\
\hline \multicolumn{7}{|l|}{ Remodeling } \\
\hline Schäfers & 2015 & 6 & 290 & 6.2 years (mixed) & 89\%@10 years,83\%@15 years & $81 \% @ 5$ years to $92 \% @ 5$ years $^{\mathrm{a}}$ \\
\hline \multicolumn{7}{|l|}{ Reimplantation } \\
\hline de Kerchove & 2011 & 21 & $53^{\mathrm{b}}$ & 73 months & 100\%@6years & 100\%@6years \\
\hline Forteza & 2013 & 57 & 51 & Median 36 months & $100 \%$ & $100 \%$ \\
\hline Kari & 2013 & 58 & 75 & 3 years & 90\%@2.8 years & $100 \%$ \\
\hline Richardt & 2015 & 59 & 30 & 6.6 years & & \\
\hline Vallabhajosyula & 2016 & 60 & $45^{\mathrm{c}}$ & 3.4 years & 100\%@5 years & 96\%@5 years \\
\hline Miyahara & 2016 & 61 & 41 & 39 months & 89\%@5 years & $83 \% @ 5$ years $^{\mathrm{d}}$ \\
\hline Fattouch & 2017 & 62 & 65 & 68 months (mixed) & 98\%@5 years & 98\%@5 years \\
\hline
\end{tabular}

${ }^{\mathrm{a}}$ Improved with annuloplasty

${ }^{\mathrm{b}}$ After matching

${ }^{\mathrm{c}}$ Type I alone

${ }^{\mathrm{d}}$ Freedom from more than mild AR 